\title{
Multi-attribute group decision making methods with proportional 2-tuple linguistic assessments and weights
}

\author{
Cong-Cong Li, Yucheng Dong* \\ Business School, Sichuan University, \\ Chengdu, 610065, P.R. China
}

Received 26 March 2013; Accepted 25 February 2014

\begin{abstract}
The proportional 2-tuple linguistic model provides a tool to deal with linguistic term sets that are not uniformly and symmetrically distributed. This study further develops multi-attribute group decision making methods with linguistic assessments and linguistic weights, based on the proportional 2-tuple linguistic model. Firstly, this study defines some new operations in proportional 2-tuple linguistic model, including weighted average aggregation operator with linguistic weights, ordered weighted average operator with linguistic weights and the distance between proportional linguistic 2-tuples. Then, four multi-attribute group decision making methods are presented. They are the method based on the proportional 2-tuple linguistic aggregation operator, technique for order preference by similarity to ideal solution (TOPSIS) with proportional 2-tuple linguistic information, elimination et choice translating reality (ELECTRE) with proportional 2-tuple linguistic information, preference ranking organization methods for enrichment evaluations (PROMETHEE) with proportional 2-tuple linguistic information. Finally, an example is given to illustrate the effectiveness of the proposed methods.
\end{abstract}

Keywords: multi-attribute group decision making, proportional 2-tuple linguistic model, linguistic weights, TOPSIS, ELECTRE, PROMETHEE

\section{Introduction}

Due to the complexity and uncertainty of decision making environment, some problems cannot be dealt with by precise and exact models. A possible way to solve such problems is the use of linguistic approaches ${ }^{15,19,20,21,34,36,39,43}$. Two different linguistic models are used in decision making, they are the models based on extension principle ${ }^{9,40,48,49}$ and the symbolic methods ${ }^{10,23,24,25,26,47}$. The models based on extension principle perform the retranslation step as an approximation process to express the results in the initial term set provoking a lack of accuracy ${ }^{26}$. To avoid such inaccuracy, Herrera and Martínez ${ }^{24}$ proposed the 2tuple linguistic model, and the Herrera and Martínez model has been successfully applied in a wide range of

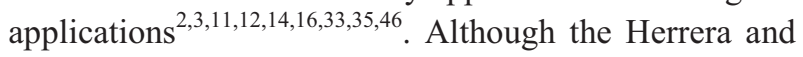
Martínez model has no loss of information, it only guarantees accuracy in dealing with uniformly and symmetrically distributed linguistic term sets. And in the real decision-making environment, the linguistic term sets that are not uniformly and symmetrically distributed may be used to express the preferences. In order to deal with this type of linguistic term sets, two different approaches based on linguistic 2-tuples have been presented.

(1) Herrera et al. $^{22}$ defined the concept of unbalanced linguistic term set, and proposed an unbalanced linguistic representation model to deal with unbalanced linguistic term set. This model is based on the use of linguistic hierarchy ${ }^{22}$ and the 2-tuple linguistic representation model ${ }^{26}$.

(2) Wang and $\mathrm{Hao}^{44,45}$ developed the proportional 2tuple linguistic representation model, and the Wang and Hao model is based on the concepts of symbolic proportion and the canonical characteristic values (CCVs). By defining the concept of numerical scale, Dong et al. ${ }^{13}$ proposed an integration of the Herrera and Martínez model and the Wang and Hao model.

Moreover, in order to extend the flexibility of the

*Corresponding author: ycdong@scu.edu.cn (Y. Dong) 
linguistic computational model, Massanet et al. ${ }^{37}$ proposed a new linguistic computational model based on discrete fuzzy numbers whose support is a subset of consecutive natural numbers. Meanwhile, Rodríguez and Martínez ${ }^{42}$ recently presented a comparative study of different symbolic linguistic computing models $\mathrm{s}^{21,24,44,47}$ in decision making.

Several decision making models based on unbalanced linguistic term sets have been presented. For example, Cabrerizo et al. ${ }^{6,7}$ presented a consensus-based group decision making with unbalanced linguistic terms. Martínez et al. ${ }^{32}$ applied the model with unbalanced linguistic terms to sensory evaluation. Herrera-Viedma and López-Herrera ${ }^{28}$ developed a model of information retrieval system with unbalanced fuzzy linguistic information. Herrera-Viedma et al. ${ }^{27}$ and Meng and $\mathrm{Pei}^{41}$ studied the linguistic aggregation operators with unbalanced linguistic information.

However, although the Wang and Hao model can handle linguistic term sets that are not uniformly and symmetrically distributed, there are little studies regarding the decision model based on the Wang and Hao model. The main aim of this paper is to develop multi-attribute group decision making methods with linguistic assessments and linguistic weights, based on the Wang and Hao model (i.e., the proportional 2-tuple linguistic model). Our proposal will provide a novel approach to deal with the multi-attribute group decision making problems, in which decision makers can comfortably express their preferences by linguistic term sets that are not uniformly and symmetrically distributed. Particularly, the weights of the decision makers are also described via a linguistic way.

The remainder of this paper is organized as follows. In Section 2, we introduce the basic knowledge regarding the proportional 2-tuple linguistic model. Then, Section 3 proposes some new operations in proportional 2-tuple linguistic model. In Section 4, four multi-attribute group decision making methods with proportional 2-tuple linguistic assessments and weights are presented. In Section 5, an illustrative example is provided and, finally, concluding remarks are included in Section 6.

\section{Preliminaries: proportional 2-tuple linguistic model}

The basic notations and operational laws of linguistic variables are introduced in ${ }^{15,19,21,22,33,34,39,48}$. Let $S=\left\{s_{i} \mid i=0,1, \ldots, n\right\}$ be a linguistic term set with odd cardinality. The term $s_{i}$ represents a possible value for linguistic variable. For example, a set of seven terms $S$ could be $S=\left\{s_{0}=\right.$ very poor,$s_{1}=$ poor,$s_{2}=$ slightly poor,$s_{3}=$ fair,$s_{4}=$ slightly good,$s_{5}=$ good,$s_{6}=$ very good $\}$. Usually, it is required that the linguistic term set $S$ should satisfy the following characteristics:

- $\quad$ The set is ordered: $s_{i}>s_{j}$, if and only if $i>j$.

- There is a negation operator: $\operatorname{Neg}\left(s_{i}\right)=s_{j}$, such that $j=n-i(n+1$ is the cardinality of $S)$

Wang and $\mathrm{Hao}^{44}$ proposed the proportional 2-tuple linguistic model, which is a new fuzzy linguistic representation model for computing with words. The proportional 2-tuple linguistic model uses the expression of proportional 2-tuples, such as $\left(0.2 S_{i}, 0.8 S_{i+1}\right)$ for the case when someone's grades in the answerscripts of a whole course are distributed as $20 \% S_{i}$ and $80 \% S_{i+1}$.

Definition $1^{44}$ : Let $S=\left\{s_{0}, s_{1}, \ldots, S_{\mathrm{n}}\right\}$ be an ordinal term set, $I=[0,1]$ and

$$
I S=I \times S=\left\{\left(\alpha, s_{i}\right): \alpha \in[0,1] \text { and } i=0,1, \ldots, n\right\} .
$$

Given a pair $\left(s_{i}, S_{i+1}\right)$ of two successive ordinal terms of $S$, any two elements $\left(\alpha, s_{i}\right),\left(\beta, s_{i+1}\right)$ of $I S$ is called a symbolic proportion pair and $\alpha, \beta$ are called a pair of symbolic proportions of the pair $\left(s_{i}, s_{i+1}\right)$ if $\alpha+\beta=1$. A symbolic proportion pair $\left(\alpha, s_{i}\right),\left(1-\alpha, s_{i+1}\right)$ will be denoted by $\left(\alpha s_{i},(1-\alpha) s_{i+1}\right)$ and the set of all the symbolic proportion pairs denoted by $\bar{S}$, i.e., $\bar{S}=\left\{\left(\alpha s_{i},(1-\alpha) s_{i+1}\right): \alpha \in[0,1]\right.$ and $\left.i=0,1, \ldots, n-1\right\}$.

In general, the element semantics in a linguistic term set are given by fuzzy numbers (defined in the $[0,1]$ interval), which are described by linear triangular membership functions or linear trapezoidal membership functions. For instance, the linear trapezoidal membership function is achieved by a 4-tuples $(a, b, c, d), b$ and $c$ indicate the interval in which the membership value is 1 , and $a$ and $d$ are the left and right limits of the definition domain of a trapezoidal membership function. The semantics of linguistic terms used in the Wang and Hao model are defined by symmetrical trapezoidal fuzzy numbers. If the semantics of $s_{i}$ is 
defined by $T\left[b_{i}-\sigma_{i}, b_{i}, c_{i}, c_{i}+\sigma_{i}\right]$, in the Wang and Hao model the canonical characteristic value ( $C C V$ ) of $s_{i}$ is

$\frac{b_{i}+c_{i}}{2}$, i.e., $C C V\left(s_{i}\right)=\frac{b_{i}+c_{i}}{2}$.

Let $S=\left\{s_{0}, S_{1}, \ldots, S_{\mathrm{n}}\right\}$ be an ordered linguistic term set and $\bar{S}$ be the linguistic proportional 2-tuple set generated by $S$. Suppose $c_{i} \in[0,1], i=0,1, \ldots, n$, with $c_{0}<c_{1}<\ldots<c_{n}$ are the canonical characteristic values $(C C V s)$ of $s_{i}$, i.e., $C C V\left(s_{i}\right)=c_{i}$.

Definition $2^{44}$ : Let $S$ and $\bar{S}$ and $C C V$ on $S$ as previously. For $\left(\alpha s_{i},(1-\alpha) s_{i+1}\right) \in \bar{S}$, the function $C C V$ on $\bar{S}$ is defined by

$C C V\left(\alpha s_{i},(1-\alpha) s_{i+1}\right)=\alpha C C V\left(s_{i}\right)+(1-\alpha) C C V\left(s_{i+1}\right)$

$=\alpha c_{i}+(1-\alpha) c_{i+1}$

Proposition $1^{44}$ : $C C V$ is a bijection from $\bar{S}$ to $\left[c_{0}, c_{n}\right]$.

In this study, the inversion of $C C V$ is denoted as $C C V^{-1}$

Definition $3^{44}$ : For any two proportional 2-tuples $\left(\alpha s_{k},(1-\alpha) s_{k+1}\right)$ and $\left(\beta s_{l},(1-\beta) s_{l+1}\right)$

(i) if $k<l$, then

(a) $\left(\alpha s_{k},(1-\alpha) s_{k+1}\right),\left(\beta s_{l},(1-\beta) s_{l+1}\right)$ represents the same information when $\alpha=0, \beta=1$ and $k=l-1$;

(b) $\left(\alpha s_{k},(1-\alpha) s_{k+1}\right)<\left(\beta s_{l},(1-\beta) s_{l+1}\right)$ otherwise.

(ii) if $k=l$, then

(a) if $\alpha=\beta$, then $\left(\alpha s_{k},(1-\alpha) s_{k+1}\right),\left(\beta s_{l},(1-\beta) s_{l+1}\right)$ represents the same information;

(b) if $\alpha<\beta$, then $\left(\alpha s_{k},(1-\alpha) s_{k+1}\right)>\left(\beta s_{l},(1-\beta) s_{l+1}\right)$;

(c) if $\alpha>\beta$, then $\left(\alpha s_{k},(1-\alpha) s_{k+1}\right)<\left(\beta s_{l},(1-\beta) s_{l+1}\right)$.

(iii)The usual negation operator of a proportional 2tuple: define the usual negation operator over proportional 2-tuples as $\operatorname{Neg}\left(\alpha s_{i},(1-\alpha) s_{i+1}\right)=$ $\left((1-\alpha) s_{n-i-1}, \alpha s_{n-i}\right)$, where $n+1$ is the cardinality of $S, S=\left\{s_{0}, s_{1}, \ldots, s_{n}\right\}$.

\section{New operations in proportional 2-tuple linguistic model}

In the real decision situations, there exist problems that need to assess their alternatives by linguistic term sets that are not uniformly and symmetrically distributed $^{21}$. In this case, the proportional 2-tuple can be used. Particularly, the weights of the decision makers (or attributes) may be also needed to be assessed by linguistic information. In order to deal with this type of problems, we present some new operations in proportional 2-tuple linguistic model, that is, weighted average aggregation operator with linguistic weights, ordered weighted average operator with linguistic weights and the distance between proportional linguistic 2-tuples.

Definition 4: Let $S=\left\{s_{0}, s_{1}, \ldots, S_{\mathrm{n}}\right\}$ be a linguistic term set and $\bar{S}$ be the linguistic proportional 2-tuple set generated by $S$. Let $S^{\prime}=\left\{s_{0}^{\prime}, s_{1}^{\prime}, \ldots, s_{g}^{\prime}\right\}$ be another linguistic term set and $\bar{S}^{\prime}$ be the linguistic proportional 2-tuple set generated by $S^{\prime}$. Let $L=\left\{l_{1}, l_{2}, \ldots, l_{m}\right\}$, where $l_{j} \in \bar{S}$, be a set of proportional 2-tuples to aggregate. Let $W=\left\{w_{1}, w_{2}, \ldots, w_{m}\right\}^{T}$, where $w_{j} \in \bar{S}^{\prime}$, be an associated proportional 2-tuple weighted vector. Then, the proportional 2-tuple weighted average operator with linguistic weights is defined as

$$
\bar{L}=C C V^{-1}\left[\frac{\sum_{j=1}^{m}\left(C C V\left(l_{j}\right) \times C C V^{\prime}\left(w_{j}\right)\right)}{\sum_{j=1}^{m} C C V^{\prime}\left(w_{j}\right)}\right] .
$$

Definition 5: Let $L=\left\{l_{1}, l_{2}, \ldots, l_{m}\right\}$, where $l_{j} \in \bar{S}$, be a set of proportional 2-tuples to aggregate. Let $W=\left\{w_{1}, w_{2}, \ldots, w_{m}\right\}$, where $w_{j} \in \bar{S}^{\prime}$, be an associated proportional 2-tuple weighted vector. Then, the proportional 2-tuple ordered weighted average (OWA) operator with linguistic weights is defined as

$$
\bar{L}^{\prime}=C C V^{-1}\left[\frac{\sum_{j=1}^{m} C C V\left(l_{\gamma(j)}\right) \times C C V^{\prime}\left(w_{j}\right)}{\sum_{j=1}^{m} C C V^{\prime}\left(w_{j}\right)}\right] .
$$

$l_{r(1)}, l_{r(2)}, \ldots, l_{r(m)}$ is a permutation of $l_{1}, l_{2}, \ldots, l_{m}$ such that $l_{r(1)} \geq l_{r(2)} \ldots \geq l_{r(m)}$.

Note 1: In this study, we use the proportional 2-tuple weighted average operator to aggregate the linguistic assessment information. And the methods are similar if we use the OW-like operator. In addition, the fusion of the weights with the information provided of the experts 
is an important step in the decision making ${ }^{8}$. However, we do not discuss this issue in this study.

Definition 6: Let $L_{1}=\left\{l_{1}^{1}, l_{2}^{1}, \ldots, l_{m}^{1}\right\}, L_{2}=\left\{l_{1}^{2}, l_{2}^{2}, \ldots, l_{m}^{2}\right\}$ be two sets of proportional 2-tuples, where $l_{i}^{1} \in L_{1}$ and $l_{i}^{2} \in L_{2}$. Then, the distance between $L_{1}$ and $L_{2}$ is defined as

$$
D\left(L_{1}, L_{2}\right)=\frac{1}{m} \sqrt{\sum_{i=1}^{m}\left(C C V\left(l_{i}^{1}\right)-C C V\left(l_{i}^{2}\right)\right)^{2}} .
$$

\section{Approaches to group decision making with linguistic assessments and linguistic weights}

The main process of multi-attribute decision making is to find the best alternative(s) from all of the feasible alternatives, where all the alternatives can be evaluated according to the attributes. In this section, we develop multi-attribute group decision making methods with linguistic assessments and linguistic weights, based on the proportional 2-tuple linguistic model.

First, we introduce several basic concepts which will be used through the rest of this paper.

Let $S=\left\{s_{0}, s_{1}, \ldots, S_{n}\right\}, S^{\prime}=\left\{s_{0}^{\prime}, s_{1}^{\prime}, \ldots, s_{g}^{\prime}\right\}, \bar{S}$ and $\bar{S}^{\prime}$ be as before. Let $A=\left\{A_{1}, A_{2}, \ldots, A_{m}\right\}(m \geq 2)$ be the set of alternatives to be evaluated by a set of experts $E=\left\{E_{1}, E_{2}, \ldots, E_{q}\right\}(q \geq 2)$, and $W=\left[w_{1}, w_{2}, \ldots, w_{q}\right]^{T}$ be the weighting vector of decision makers, where $w_{k} \in \bar{S}^{\prime}$. Let $C=\left\{C_{1}, C_{2}, \ldots, C_{n}\right\}(n \geq 2)$ be the set of attributes, and $H=\left[h_{1}, h_{2}, \ldots, h_{n}\right]^{T}$ be the weighting vector of attributes, where $h_{k} \in \bar{S}^{\prime}$. Then the decision making matrix of $k$ th decision maker can be expressed as

$$
X^{k}=\left(\begin{array}{ccc}
x_{11}^{(k)} & \ldots & x_{1 n}^{(k)} \\
\vdots & \ddots & \vdots \\
x_{m 1}^{(k)} & \ldots & x_{m n}^{(k)}
\end{array}\right), \quad x_{i j}^{(k)} \in \bar{S}
$$

\subsection{Method based on the proportional 2-tuple linguistic aggregation operator}

In the method based on the proportional 2-tuple linguistic aggregation operator, in order to obtain the best alternative(s), the proportional 2-tuple weighted average operator with linguistic weights is employed to aggregate the linguistic evaluation values of all experts using the weights of decision makers, and then the operator is again used to derive the collective overall preference value of each alternative using the weight of each attribute. This method consists of the following steps.

Step 1: Utilizing the proportional 2-tuple weighted average operator with linguistic weights, linguistic evaluation matrices $x^{1}, x^{2}, \ldots, x^{q}$ and the weighting vector of decision makers $w_{1}, w_{2}, \ldots, w_{q}$ are aggregated into a group comprehensive evaluation matrix $L$

$$
L_{i j}=C C V^{-1}\left[\frac{\sum_{k=1}^{q} C C V\left(x_{i j}^{k}\right) \times C C V^{\prime}\left(w_{k}\right)}{\sum_{k=1}^{q} C C V^{\prime}\left(w_{k}\right)}\right], i=1,2, \ldots, m, j=1,2, \ldots, n .
$$

Step 2: Utilizing the weighted average operator with linguistic weights to derive the collective overall preference value $L_{i}$ of the alternative $A_{i}$.

$L_{i}=C C V^{-1}\left[\frac{\sum_{j=1}^{n} C C V\left(l_{i j}\right) \times C C V^{\prime}\left(h_{j}\right)}{\sum_{j=1}^{n} C C V^{\prime}\left(h_{j}\right)}\right], i=1,2, \ldots, m$.

Step 3: Rank all the alternatives $A_{i}(i=1,2, \ldots, m)$ and select the best one(s) in accordance with $L_{i}$. If any alternative has the highest $L_{i}$ value, then it is the most important alternative(s).

\subsection{TOPSIS with proportional 2-tuple linguistic information}

Technique for order preference by similarity to ideal solution (TOPSIS), developed by Hwang and Yoon in $1981^{29}$ is a simple ranking method in conception and application. For the TOPSIS with proportional 2-tuple linguistic information, the optimal alternative(s) is determined by calculating the distances of every alternative from the positive-ideal solution and negative-ideal solution. It is based on the concept that the optimal alternative(s) should have the shortest distance from the positive-ideal solution and on the other side the farthest distance of the negative-ideal solution. The steps are as follows.

Step 1: This step is same as the step 1 in Section 4.1. 
Step 2: Determine the positive-ideal solution $l^{+}$and negative-ideal solution $l^{-}$, respectively,

the positive-ideal solution

$l^{+}=\left\{l_{1}^{+}, l_{2}^{+}, \ldots, l_{n}^{+}\right\}, \quad l_{j}^{+} \in l^{+}$

the negative-ideal solution

$l^{-}=\left\{l_{1}^{-}, l_{2}^{-}, \ldots, l_{n}^{-}\right\}, \quad l_{j}^{-} \in l^{-}$

where

$l_{j}^{+}=\max \left\{l_{i j}\right\}, l_{j}^{-}=\min \left\{l_{i j}\right\}, i=1,2, \ldots, m, j=1,2, \ldots, n$.

Step 3: Calculate the distances of each alternative from the positive-ideal solution and negative-ideal solution, respectively,

$$
\begin{aligned}
& D_{i}^{+}=\frac{1}{n} \sqrt{\sum_{j=1}^{n}\left(C C V\left(l_{i j}\right)-C C V\left(l_{j}^{+}\right)\right)^{2}}, i=1,2, \ldots, m . \\
& D_{i}^{-}=\frac{1}{n} \sqrt{\sum_{j=1}^{n}\left(C C V\left(l_{i j}\right)-C C V\left(l_{j}^{-}\right)\right)^{2}}, i=1,2, \ldots, m .
\end{aligned}
$$

Step 4: Calculate the relative closeness degree of each alternative to the positive-ideal solution using the following equation

$$
\xi_{i}=\frac{D_{i}^{-}}{D_{i}^{+}+D_{i}^{-}}
$$

Rank the alternatives according to the relative closeness to the ideal solution. If any alternative has the highest $\xi_{i}$ value, then it is the most important alternative(s).

\subsection{ELECTRE with proportional 2-tuple linguistic information}

The methodologies in the elimination et choice translating reality (ELECTRE) ${ }^{5}$ family are the most widely used outranking methods for multiple criteria decision analysis ${ }^{17}$. The family of ELECTRE methods includes ELECTRE I, II, III, IV and TRI ${ }^{38}$. In this paper, based on ELECTRE II, we propose the ELECTRE with proportional 2-tuple linguistic information, which leads to a complete ranking of the alternatives by means of three thresholds for concordance conditions and two thresholds for discordance conditions. The steps are as follows.

Step 1: This step is same as the step1 in Section 4.1.
Step 2: Determination of the concordance conditions.

(i) If $A_{i}$ in the attribute $C_{j}$ is superior to $A_{k}$ $(i, k=1,2, \ldots, m, i \neq k)$, denoted as $A_{i} \succ_{j} A_{k}$. With $J=\{1,2, \ldots, n\}$, let the following quantities be defined:

$$
\begin{aligned}
& J^{+}\left(A_{i}, A_{k}\right)=\left\{j \mid 1 \leq j \leq n, l_{i j}>l_{k j}\right\} \\
& J^{=}\left(A_{i}, A_{k}\right)=\left\{j \mid 1 \leq j \leq n, l_{i j}=l_{k j}\right\} \\
& J^{-}\left(A_{i}, A_{k}\right)=\left\{j \mid 1 \leq j \leq n, l_{i j}<l_{k j}\right\}
\end{aligned}
$$

where $J^{+}\left(A_{i}, A_{k}\right)$ is the set of criteria for which $A_{i}$ is preferred to $A_{k}, J^{=}\left(A_{i}, A_{k}\right)$ is the set of criteria for which $A_{i}$ is equal to $A_{k}, J^{-}\left(A_{i}, A_{k}\right)$ is the set of criteria for which $A_{i}$ is not preferred to $A_{k}, l_{i j}$ represents the performance of alternative $A_{i}$ in terms of criterion $C_{j}$, and $l_{k j}$ represents the performance of alternative $A_{k}$ in terms of criterion $C_{j}$.

(ii) Computing the concordance index. The concordance index for a pair of alternatives $A_{i}$ and $A_{k}$ measures the strength of the hypothesis that alternative $A_{i}$ is at least as good as alternatives $A_{k}$. The concordance condition for the pair $\left(A_{i}, A_{k}\right)$ is defined as follows:

$$
\begin{aligned}
I_{i k}=\frac{\sum_{\mathrm{j} \in J^{+}\left(A_{i}, A_{k}\right)} \operatorname{CCV}\left(h_{j}\right)+\sum_{j \in J^{\prime}\left(A_{i}, A_{k}\right)} \operatorname{CCV}\left(h_{j}\right)}{\sum_{j}^{n} \operatorname{CCV}\left(h_{j}\right)} \geq \hat{a} \\
\bar{I}_{i k}=\frac{\sum_{\mathrm{j} \in J^{+}\left(A_{i}, A_{k}\right)} \operatorname{CCV}\left(h_{j}\right)}{\sum_{j \in J^{-}\left(A_{i}, A_{k}\right)} \operatorname{CCV}\left(h_{j}\right)} \geq 1
\end{aligned}
$$

Where $\hat{a}$ is a number reflecting a minimum acceptable level of concordance, usually set at $0.5, h_{j}$ is the weight of the $j$ th criterion, $\bar{I}_{i k}$ measures the strength of the hypothesis that alternative $A_{i}$ is good at alternative $A_{k}$.

Step 3: Determination of the discordance conditions.

The discordance condition is introduced to handle the criteria for which $A_{i}$ is not preferred to $A_{k}$; for those criteria, the decision maker specifies the maximum level of discordance which can be tolerated. Assuming the thresholds of each criterion are $d_{j}^{0}, d_{j}^{*}\left(d_{j}^{0}<d_{j}^{*}\right)$, and the three discordance sets are defined as: 
High (unacceptable) discordance:

$D_{j}^{h}=\left\{\left(l_{i j}, l_{k j}\right) \mid C C V\left(l_{i j}\right)-C C V\left(l_{k j}\right) \geq d_{j}^{*}, i, k=1,2, \ldots, m, i \neq k\right\}$

Average discordance:

$D_{j}^{m}=\left\{\left(l_{i j}, l_{k j}\right) \mid d_{j}^{o} \leq C C V\left(l_{i j}\right)-C C V\left(l_{k j}\right) \leq d_{j}^{*}, i, k=1,2, \ldots, m\right.$,

$i \neq k\}$

Low discordance:

$D_{j}^{l}=\left\{\left(l_{i j}, l_{k j}\right) \mid C C V\left(l_{i j}\right)-C C V\left(l_{k j}\right) \leq d_{j}^{o}, i, k=1,2, \ldots, m, i \neq k\right\}$

Step 4: Define the strong and weak outranking relationship.

After the determination of the concordance and discordance conditions, two types of outranking relations can be built by comparing the indices with two pairs of threshold values. Similar to the discordance thresholds $d_{j}^{o}, d_{j}^{*}$, the concordance thresholds are decided by the decision makers. Let $a^{h}, a^{m}, a^{l}$ be three decreasing levels of concordance, say, 'high', 'average' and 'low', such that $1 \geq a^{h} \geq a^{m} \geq a^{l} \geq 0.5$.

Then, according to the concordance thresholds and three discordance sets, the strong and weak outranking relations are defined as follows:

(i) $A_{i}$ strongly outranks $A_{k}$ if

(a) The concordance is high and the discordance is average.

(b) The concordance is average and the discordance is low.

i.e., $\bar{I}_{i k} \geq 1$ and,
(a) $I_{i k} \geq a^{h}$ and $\left(l_{i j}, l_{k j}\right) \in D_{j}^{m}, j \in J^{-}\left(A_{i}, A_{k}\right)$.
(b) $I_{i k} \geq a^{m}$ and $\left(l_{i j}, l_{k j}\right) \in D_{j}^{l}, j \in J^{-}\left(A_{i}, A_{k}\right)$.
(ii) $A_{i}$ weakly outranks $A_{k}$ if

(a) Both concordance and discordance are low.

(b) Both concordance and discordance are average. i.e., $\bar{I}_{i k} \geq 1$ and,

(a) $I_{i k} \geq a^{m}$ and $\left(l_{i j}, l_{k j}\right) \in D_{j}^{m}, j \in J^{-}\left(A_{i}, A_{k}\right)$.

(b) $I_{i k} \geq a^{l}$ and $\left(l_{i j}, l_{k j}\right) \in D_{j}^{l}, j \in J^{-}\left(A_{i}, A_{k}\right)$.

Step 5: According to the strong preference relationship and weak preference relationship, we can get a forward ranking $V\left(A_{i}\right)$ and a reverse ranking $U\left(A_{i}\right)$. Then, in order to define a final ranking $Z\left(A_{i}\right)$ between $U\left(A_{i}\right)$ and $V\left(A_{i}\right)$, utilizing the following equations
$U^{*}=\max \left(U\left(A_{i}\right)\right) ; U^{\prime}\left(A_{i}\right)=1+U^{*}-U\left(A_{i}\right) ;$

$Z\left(A_{i}\right)=\frac{V\left(A_{i}\right)+U^{\prime}\left(A_{i}\right)}{2}$.

Step 6: Rank all the alternatives $A_{i}(i=1,2, \ldots, m)$ and select the best one(s) in accordance with $Z\left(A_{i}\right)$.

\subsection{PROMETHEE with proportional 2-tuple linguistic information}

Besides ELECTRE methods, preference ranking organization methods for enrichment evaluations (PROMETHEE) methods are the other most extensively used outranking relation theory techniques ${ }^{4}$. The family of PROMETHEE methods is suitable for ranking and selecting from among a finite set of alternative actions, especially PROMETHEE $\mathrm{I}$ and $\mathrm{II}^{1,18}$. Based on PROMETHEE II, the PROMETHEE with proportional 2-tuple linguistic information is intended to provide a complete ranking of a finite set of feasible alternatives from the best to the worst, and the basic principle of this method is based on the pair-wise comparison of alternatives along each selected criterion. The steps are as follows.

Step 1: This step is same as the step1 in Section 4.1.

Step2: Determination of performance differences, the performance difference between each pair of alternatives with respect to each criterion is calculated as follows:

$$
d_{j}\left(A_{i}, A_{k}\right)=C C V\left(l_{i j}\right)-C C V\left(l_{k j}\right)
$$

where $l_{i j}$ and $l_{k j}$ show the performance of alternatives $A_{i}$ and $A_{k}$, respectively, with regard to criterion $j$, and $d_{j}\left(A_{i}, A_{k}\right)$ denotes the difference between these performances.

Step 3: Application of the preference functions, for each criterion, the preference function can be represented as follows:

$$
P_{j}\left(A_{i}, A_{k}\right)=F\left(d_{j}\left(A_{i}, A_{k}\right)\right), j=1,2, \ldots, m .
$$

where $P_{j}\left(A_{i}, A_{k}\right)$ denotes the preference of alternative $A_{i}$ over alternative $A_{k}$ with respect to criterion $j$ as a function of $d_{j}\left(A_{i}, A_{k}\right)$.

Although decision makers can select many different types (e.g., quasi criterion, level criterion, criterion with 
linear preference) of preference functions for each criterion and certain preferential parameters must be specified for each function, for the sake of simplicity, this study uses criterion with linear preference as the preference function for each criterion. The criterion with linear preference $H(d)$ is defined as follows:

$$
H(d)= \begin{cases}|d| / m & -m \leq d \leq m \\ 1 & d>m \text { or } \mathrm{d}<-m\end{cases}
$$

where $m$ is a preferential parameter that may be determined by decision makers.

Step 4: Calculation of the global preference indices, for each pair of alternatives, an aggregated preference index is calculated as follows:

$$
\pi\left(A_{i}, A_{k}\right)=\sum_{j=1}^{m} C C V\left(h_{j}\right) P_{j}\left(A_{i}, A_{k}\right)
$$

where $\pi\left(A_{i}, A_{k}\right)$ denotes an overall preference index which reveals the intensity of the preference for $A_{i}$ over $A_{k}$.

Step 5: Define the leaving flow, entering flow and net flow of the alternatives.

$$
\begin{aligned}
& \text { Leaving flow: } \phi^{+}\left(A_{i}\right)=\sum \pi\left(A_{i}, A_{k}\right) \\
& \text { Entering flow: } \phi^{-}\left(A_{i}\right)=\sum \pi\left(A_{k}, A_{i}\right)
\end{aligned}
$$

$\phi^{+}\left(A_{i}\right)$ represents the outranking character of $A_{i}$ over all training patterns, and $\phi^{-}\left(A_{i}\right)$ represents the outranked character of $A_{i}$ by all training patterns, then the net flow of alternative $A_{i}$ can be calculated as follows

$$
\phi\left(A_{i}\right)=\phi^{+}\left(A_{i}\right)-\phi^{-}\left(A_{i}\right)
$$

Then, a complete ranking of the alternatives can be obtained by the net flows, and the alternative with the highest net flow is superior.

\section{Illustrative example}

In order to show how the methods with proportional 2-tuple linguistic assessments and linguistic weights work in practice, let us consider the following example.

Suppose that a company wants to enhance its IT construction. After preliminary screening, four feasible governance programs $A_{1}, A_{2}, A_{3}, A_{4}$ remain for further evaluation. An expert committee of four decision makers $D_{1}, D_{2}, D_{3}, D_{4}$ has been formed to conduct the evaluation and to select the most suitable IT governance program(s) for the company. Five criteria in accordance with the characteristics of IT governance are considered: $C_{1}-$ IT principles; $C_{2}-$ IT architecture; $C_{3}-$ IT infrastructure strategies; $C_{4}-$ Business applications; $C_{5}$ - IT investment and prioritization.

Assume that the decision makers express their preferences by means of linguistic assessments from the ordered linguistic term set of seven labels:

$S=\left\{S_{0}=V B(\right.$ Very Bad $), S_{1}=B($ Bad $), S_{2}=M B($ Medium

Bad $), S_{3}=M($ Medium $), S_{4}=M G($ Medium Good $)$,

$S_{5}=G($ Good $), S_{6}=V G($ Very Good $\left.)\right\}$

We can express the weights of decision makers (or attributes) by means of linguistic assessments from the ordered linguistic term set of five labels : $S^{\prime}=\left\{S_{0}^{\prime}=N(\right.$ None $), S_{1}^{\prime}=N I($ Not Important $), S_{2}^{\prime}=M($ Medium $)$, $S_{3}^{\prime}=I($ Important $), S_{4}^{\prime}=V I($ Very Important $\left.)\right\}$.

The initial evaluation matrices $X^{k}$ provided by the decision makers $D_{k}(k=1,2,3,4)$ are listed as Tables 1 4. Table 5 defines both the CCV and trapezoidal fuzzy numbers in $[0,1]$ of each label in $S$. Table 6 defines both the CCV and trapezoidal fuzzy numbers in $[0,1]$ of each label in $S^{\prime}$.

Table 5. The CCV and trapezoidal fuzzy numbers in $[0,1]$ of each label in $S$

\begin{tabular}{clc}
\hline Linguistic variable & Fuzzy number & CCV \\
\hline$S_{0}$ & {$[0,0,0,0]$} & 0 \\
$S_{1}$ & {$[0,0.03,0.10,0.13]$} & 0.065 \\
$S_{2}$ & {$[0.10,0.20,0.25,0.35]$} & 0.225 \\
$S_{3}$ & {$[0.33,0.45,0.55,0.67]$} & 0.5 \\
$S_{4}$ & {$[0.5,0.6,0.65,0.75]$} & 0.625 \\
$S_{5}$ & {$[0.7,0.8,0.9,1]$} & 0.85 \\
$S_{6}$ & {$[1,1,1,1]$} & 1 \\
\hline
\end{tabular}

Table 6. The CCV and trapezoidal fuzzy numbers in $[0,1]$ of each label in $S^{\prime}$

\begin{tabular}{clc}
\hline Linguistic variable & Fuzzy number & CCV \\
\hline$S_{0}^{\prime}$ & {$[0,0,0,0]$} & 0 \\
$S_{1}^{\prime}$ & {$[0,0.2,0.3,0.5]$} & 0.25 \\
$S_{2}^{\prime}$ & {$[0.35,0.45,0.55,0.65]$} & 0.5 \\
$S_{3}^{\prime}$ & {$[0.5,0.7,0.8,1]$} & 0.75 \\
$S_{4}^{\prime}$ & {$[1,1,1,1]$} & 1 \\
\hline
\end{tabular}


The information about the weights of decision makers and attributes are known as follows

$$
\begin{aligned}
& W^{T}=\left\{\left(0.2 S_{3}^{\prime}, 0.8 S_{4}^{\prime}\right),\left(0.77 S_{2}^{\prime}, 0.23 S_{3}^{\prime}\right),\left(0.5 S_{0}^{\prime}, 0.5 S_{1}^{\prime}\right),\right. \\
& \left.\left(0.46 S_{1}^{\prime}, 0.54 S_{2}^{\prime}\right)\right\} \\
& H^{T}=\left\{\left(0.3 S_{3}^{\prime}, 0.7 S_{4}^{\prime}\right),\left(0.44 S_{2}^{\prime}, 0.56 S_{3}^{\prime}\right),\left(0.2 S_{0}^{\prime}, 0.8 S_{1}^{\prime}\right),\right. \\
& \left.\left(0.19 S_{1}^{\prime}, 0.81 S_{2}^{\prime}\right),\left(0.88 S_{2}^{\prime}, 0.12 S_{3}^{\prime}\right)\right\}
\end{aligned}
$$

Utilizing Eq. (1) to aggregate linguistic rating values of four experts for each alternative and then we can obtain the group comprehensive evaluation matrix $L$, as shown in Table 7.

In the following, we shall utilize the proposed four approaches in this paper getting the most desirable alternative(s).

Table 1 . The linguistic evaluation matrix $X^{1}$ provided by the decision maker $D_{1}$

\begin{tabular}{cccccc}
\hline$X^{1}$ & $C_{1}$ & $C_{2}$ & $C_{3}$ & $C_{4}$ & $C_{5}$ \\
\hline$A_{1}$ & $\left(0.8 S_{0}, 0.2 S_{1}\right)$ & $\left(0.68 S_{2}, 0.32 S_{3}\right)$ & $\left(0.04 S_{2}, 0.96 S_{3}\right)$ & $\left(0.81 S_{2}, 0.19 S_{3}\right)$ & $\left(0.5 S_{5}, 0.5 S_{6}\right)$ \\
$A_{2}$ & $\left(0.5 S_{0}, 0.5 S_{1}\right)$ & $\left(0.2 S_{1}, 0.8 S_{2}\right)$ & $\left(0.55 S_{2}, 0.45 S_{3}\right)$ & $\left(0.5 S_{4}, 0.5 S_{5}\right)$ & $\left(0.7 S_{5}, 0.3 S_{6}\right)$ \\
$A_{3}$ & $\left(0.4 S_{1}, 0.6 S_{2}\right)$ & $\left(0.2 S_{1}, 0.8 S_{2}\right)$ & $\left(0.5 S_{5}, 0.5 S_{6}\right)$ & $\left(0.35 S_{4}, 0.65 S_{5}\right)$ & $\left(0.18 S_{3}, 0.82 S_{4}\right)$ \\
$A_{4}$ & $\left(0.3 S_{4}, 0.7 S_{5}\right)$ & $\left(0.2 S_{0}, 0.8 S_{1}\right)$ & $\left(0.18 S_{3}, 0.82 S_{4}\right)$ & $\left(0.4 S_{0}, 0.6 S_{1}\right)$ & $\left(0.2 S_{1}, 0.8 S_{2}\right)$ \\
\hline
\end{tabular}

Table 2. The linguistic evaluation matrix $X^{2}$ provided by the decision maker $D_{2}$

\begin{tabular}{cccccc}
\hline$X^{2}$ & $C_{1}$ & $C_{2}$ & $C_{3}$ & $C_{4}$ & $C_{5}$ \\
\hline$A_{1}$ & $\left(0.3 S_{1}, 0.7 S_{2}\right)$ & $\left(0.68 S_{2}, 0.32 S_{3}\right)$ & $\left(0.6 S_{4}, 0.4 S_{5}\right)$ & $\left(0.44 S_{3}, 0.56 S_{4}\right)$ & $\left(0.9 S_{5}, 0.1 S_{6}\right)$ \\
$A_{2}$ & $\left(0.2 S_{0}, 0.8 S_{1}\right)$ & $\left(0.55 S_{2}, 0.45 S_{3}\right)$ & $\left(0.55 S_{2}, 0.45 S_{3}\right)$ & $\left(0.7 S_{5}, 0.3 S_{6}\right)$ & $\left(0.18 S_{3}, 0.82 S_{4}\right)$ \\
$A_{3}$ & $\left(0.5 S_{4}, 0.5 S_{5}\right)$ & $\left(0.2 S_{2}, 0.8 S_{3}\right)$ & $\left(0.1 S_{0}, 0.9 S_{1}\right)$ & $\left(0.68 S_{2}, 0.32 S_{3}\right)$ & $\left(0.4 S_{4}, 0.6 S_{5}\right)$ \\
$A_{4}$ & $\left(0.6 S_{5}, 0.4 S_{6}\right)$ & $\left(0.4 S_{4}, 0.6 S_{5}\right)$ & $\left(0.35 S_{4}, 0.65 S_{5}\right)$ & $\left(0.4 S_{1}, 0.6 S_{2}\right)$ & $\left(0.7 S_{5}, 0.3 S_{6}\right)$
\end{tabular}

Table 3. The linguistic evaluation matrix $X^{3}$ provided by the decision maker $D_{3}$

\begin{tabular}{cccccc}
\hline$X^{3}$ & \multicolumn{1}{c}{$C_{1}$} & $C_{2}$ & $C_{3}$ & $C_{4}$ & $C_{5}$ \\
\hline$A_{1}$ & $\left(0.74 S_{2}, 0.26 S_{3}\right)$ & $\left(0.5 S_{0}, 0.5 S_{1}\right)$ & $\left(0.44 S_{3}, 0.56 S_{4}\right)$ & $\left(0.9 S_{5}, 0.1 S_{6}\right)$ & $\left(0.5 S_{5}, 0.5 S_{6}\right)$ \\
$A_{2}$ & $\left(0.2 S_{0}, 0.8 S_{1}\right)$ & $\left(0.55 S_{2}, 0.45 S_{3}\right)$ & $\left(0.68 S_{2}, 0.32 S_{3}\right)$ & $\left(0.55 S_{2}, 0.45 S_{3}\right)$ & $\left(0.3 S_{5}, 0.7 S_{6}\right)$ \\
$A_{3}$ & $\left(0.72 S_{3}, 0.28 S_{4}\right)$ & $\left(0.44 S_{3}, 0.56 S_{4}\right)$ & $\left(0.7 S_{5}, 0.3 S_{6}\right)$ & $\left(0.2 S_{0}, 0.8 S_{1}\right)$ & $\left(0.68 S_{2}, 0.32 S_{3}\right)$ \\
$A_{4}$ & $\left(0.2 S_{4}, 0.8 S_{5}\right)$ & $\left(0.18 S_{3}, 0.82 S_{4}\right)$ & $\left(0.2 S_{1}, 0.8 S_{2}\right)$ & $\left(0.43 S_{2}, 0.57 S_{3}\right)$ & $\left(0.4 S_{1}, 0.6 S_{2}\right)$ \\
\hline
\end{tabular}

Table 4. The linguistic evaluation matrix $X^{4}$ provided by the decision maker $D_{4}$

\begin{tabular}{cccccc}
\hline$X^{4}$ & \multicolumn{1}{c}{$C_{1}$} & \multicolumn{1}{c}{$C_{2}$} & \multicolumn{1}{c}{$C_{3}$} & \multicolumn{1}{c}{$C_{4}$} & $C_{5}$ \\
\hline$A_{1}$ & $\left(0.87 S_{2}, 0.13 S_{3}\right)$ & $\left(0.55 S_{2}, 0.45 S_{3}\right)$ & $\left(0.1 S_{0}, 0.9 S_{1}\right)$ & $\left(0.68 S_{2}, 0.32 S_{3}\right)$ & $\left(0.2 S_{5}, 0.8 S_{6}\right)$ \\
$A_{2}$ & $\left(0.7 S_{1}, 0.3 S_{2}\right)$ & $\left(0.2 S_{0}, 0.8 S_{1}\right)$ & $\left(0.44 S_{3}, 0.56 S_{4}\right)$ & $\left(0.4 S_{0}, 0.6 S_{1}\right)$ & $\left(0.28 S_{2}, 0.72 S_{3}\right)$ \\
$A_{3}$ & $\left(0.5 S_{0}, 0.5 S_{1}\right)$ & $\left(0.72 S_{3}, 0.28 S_{4}\right)$ & $\left(0.3 S_{5}, 0.7 S_{6}\right)$ & $\left(0.4 S_{4}, 0.6 S_{5}\right)$ & $\left(0.5 S_{4}, 0.5 S_{5}\right)$ \\
$A_{4}$ & $\left(0.5 S_{5}, 0.5 S_{6}\right)$ & $\left(0.7 S_{5}, 0.3 S_{6}\right)$ & $\left(0.2 S_{0}, 0.8 S_{1}\right)$ & $\left(0.04 S_{2}, 0.96 S_{3}\right)$ & $\left(0.3 S_{5}, 0.7 S_{6}\right)$ \\
\hline
\end{tabular}


Table 7. The group comprehensive evaluation matrix $L$

\begin{tabular}{cccccc}
\hline$L$ & $C_{1}$ & $C_{2}$ & $C_{3}$ & $C_{4}$ & $C_{5}$ \\
\hline$A_{1}$ & $\left(0.64 S_{1}, 0.36 S_{2}\right)$ & $\left(0.72 S_{2}, 0.28 S_{3}\right)$ & $\left(0.09 S_{2}, 0.91 S_{3}\right)$ & $\left(0.36 S_{2}, 0.64 S_{3}\right)$ & $\left(0.56 S_{5}, 0.44 S_{6}\right)$ \\
$A_{2}$ & $\left(0.16 S_{0}, 0.84 S_{1}\right)$ & $\left(0.04 S_{1}, 0.96 S_{2}\right)$ & $\left(0.41 S_{2}, 0.59 S_{3}\right)$ & $\left(S_{4}\right)$ & $\left(0.54 S_{4}, 0.46 S_{5}\right)$ \\
$A_{3}$ & $\left(0.65 S_{2}, 0.35 S_{3}\right)$ & $\left(0.54 S_{2}, 0.46 S_{3}\right)$ & $\left(0.73 S_{4}, 0.27 S_{5}\right)$ & $\left(0.22 S_{3}, 0.78 S_{4}\right)$ & $\left(0.87 S_{4}, 0.13 S_{5}\right)$ \\
$A_{4}$ & $\left(S_{5}\right)$ & $\left(0.21 S_{2}, 0.79 S_{3}\right)$ & $\left(0.84 S_{3}, 0.16 S_{4}\right)$ & $\left(0.28 S_{1}, 0.72 S_{2}\right)$ & $\left(0.68 S_{3}, 0.32 S_{4}\right)$
\end{tabular}

(1) Ranking the alternatives: method based on proportional 2-tuple linguistic aggregation operator

According to the group comprehensive evaluation matrix $L$, utilizing Eq. (2) to calculate the comprehensive evaluation value of four alternatives, and we obtain

$$
\begin{aligned}
& Z\left(A_{1}\right)=\left(0.4 S_{2}, 0.6 S_{3}\right), Z\left(A_{2}\right)=\left(0.58 S_{2}, 0.42 S_{3}\right), \\
& Z\left(A_{3}\right)=\left(0.13 S_{2}, 0.87 S_{3}\right), Z\left(A_{4}\right)=\left(0.52 S_{3}, 0.48 S_{4}\right) .
\end{aligned}
$$

Ranking all the alternatives $A_{i}(i=1,2,3,4)$ in accordance with the comprehensive evaluation value $Z\left(A_{i}\right)$, we can obtain $A_{4} \succ A_{3} \succ A_{1} \succ A_{2}$, and thus the most desirable alternative is $A_{4}$.

\section{(2) Ranking the alternatives: TOPSIS with proportional 2-tuple linguistic information}

According to the group comprehensive evaluation matrix $L$, define the positive-ideal solution and negative-ideal solution as

the positive-ideal solution:

$\left\{\left(S_{5}\right),\left(0.21 S_{2}, 0.79 S_{3}\right),\left(0.73 S_{4}, 0.27 S_{5}\right),\left(S_{4}\right)\right.$,

$$
\left.\left(0.56 S_{5}, 0.44 S_{6}\right)\right\}
$$

the negative-ideal solution:

$\left\{\left(0.16 S_{0}, 0.84 S_{1}\right),\left(0.04 S_{1}, 0.96 S_{2}\right),\left(0.41 S_{2}, 0.59 S_{3}\right),(0.2\right.$

$$
\left.\left.8 S_{1}, 0.72 S_{2}\right),\left(0.68 S_{3}, 0.32 S_{4}\right)\right\}
$$

Utilizing Eq. (3) to calculate the distances of each alternative from the positive-ideal solution and negative-ideal solution. We obtain

$$
\begin{array}{ll}
d_{1}^{+}=0.1598 & d_{1}^{-}=0.0915 \\
d_{2}^{+}=0.1792 & d_{2}^{-}=0.0966 \\
d_{3}^{+}=0.1191 & d_{3}^{-}=0.1207 \\
d_{4}^{+}=0.1212 & d_{4}^{-}=0.1668
\end{array}
$$

Calculating the relative closeness degree of each alternative from the positive-ideal solution by Eq. (4), and we obtain $\xi_{1}=0.3641, \xi_{2}=0.3502, \xi_{3}=0.5034$, $\xi_{4}=0.5792$.

Then, rank all the alternatives $A_{i}(i=1,2,3,4)$ in accordance with the relative closeness degree $\xi_{i}$, we can obtain $A_{4} \succ A_{3} \succ A_{1} \succ A_{2}$, and obviously the most desirable alternative is $A_{4}$.

\section{(3) Ranking the alternatives: ELECTRE with proportional 2-tuple linguistic information}

According to the group comprehensive evaluation matrix $L$, we can compute the concordance index based on Eq. (5). Such as $A_{1}, A_{2}$ for the case, $A_{1}$ is preferred to $A_{2}$ in the criteria $C_{1}, C_{2}, C_{3}$ and $C_{5}$, and $A_{1}$ is worse than $A_{2}$ in the criteria $C_{4}$, then $J^{+}\left(A_{1}, A_{2}\right)=\{1,2,3,5\}$, $J^{-}\left(A_{1}, A_{2}\right)=\{4\}, I_{12}=0.84, \bar{I}_{12}=5.07$.

Table 8 presents the concordance index for each pair of alternatives.

Referring to ELECTRE method, in terms of the concordance and discordance thresholds, we have assumed that $a^{l}=0.5, a^{m}=0.56, a^{h}=0.7$, and $d_{j}^{0}, d_{j}^{*}$ are presented in Table 9.

Having calculated the concordance index and the thresholds of five criteria, we get the strong preference relationship and weak preference relationship by following the steps in Section 4.3, that is, $A_{1}$ strongly preferred to $A_{2}, A_{3}$ strongly preferred to $A_{1}, A_{3}$ weakly preferred to $A_{2}, A_{4}$ weakly preferred to $A_{3}$. Let $P$ be denoted as the strong preference relationship, and $Q$ be denoted as the weak preference relationship, then the strong preference relationship $a$ is, $A_{3} P A_{1}, A_{1} P A_{2}$, the weak preference relationship $b$ is, $A_{4} Q A_{1}, A_{4} Q A_{3}, A_{3} Q A_{2}$. 
Table 8. The concordance index for each pair of alternatives

\begin{tabular}{cccccc}
\hline$A_{j}, A_{k}$ & $J^{+}(j, k)$ & $J^{-}(j, k)$ & $J^{-}(j, k)$ & $I_{j k}$ & $\bar{I}_{j k}$ \\
\hline 1,2 & $1,2,3,5$ & ---- & 4 & 0.84 & 5.07 \\
1,3 & 5 & ---- & $1,2,3,4$ & 0.19 & 0.24 \\
1,4 & 4,5 & ---- & $1,2,3$ & 0.36 & 0.56 \\
2,1 & 4 & ---- & $1,2,3,5$ & 0.16 & 0.20 \\
2,3 & 4,5 & ---- & $1,2,3$ & 0.36 & 0.56 \\
2,4 & 4,5 & ---- & $1,2,3$ & 0.36 & 0.56 \\
3,1 & $1,2,3,4$ & ---- & 5 & 0.81 & 4.18 \\
3.2 & $1,2,3$ & ---- & 4,5 & 0.64 & 1.79 \\
3,4 & $3,4,5$ & ---- & 1,2 & 0.43 & 0.76 \\
4,1 & $1,2,3$ & ---- & 4,5 & 0.64 & 1.79 \\
4,2 & $1,2,3$ & ---- & 4,5 & 0.64 & 1.79 \\
4,3 & 1,2 & ---- & $3,4,5$ & 0.57 & 1.32 \\
\hline
\end{tabular}

Table 9. The thresholds of each criterion

\begin{tabular}{lrrrrl}
\hline Criterion & $C_{1}$ & $C_{2}$ & $C_{3}$ & $C_{4}$ & $C_{5}$ \\
\hline$d_{j}^{0}$ & 0.06 & 0.09 & 0.1 & 0.2 & 0.02 \\
$d_{j}^{*}$ & 0.5 & 0.2 & 0.2 & 0.42 & 0.23 \\
\hline
\end{tabular}

Having obtained the strong and weak preference relationships, the direct ranking of the alternatives is reached using the following steps:

(1) Identify non-inferiority scheme sets from the preference relationship $a$ and $b$, we can get $Y_{a}^{1}=\{3,4\}, \quad Y_{b}^{1}=\{4\}$, their intersection is $Y^{1}=\{4\}$.

(2) Remove $A_{4}$ from the preference relationship $a$ and $b$, and then get a new set of non-inferiority schemes, that is, $Y_{a}^{2}=\{3\}, Y_{b}^{2}=\{1,3\}$, and their intersection is $Y^{2}=\{3\}$ 。

(3) Similarly, we can get $Y^{3}=\{1\}, \quad Y^{4}=\{2\}$. And the direct ranking $Y\left(A_{i}\right)$ is presented in Table 10 .

Table 10. Direct ranking

\begin{tabular}{cc}
\hline Scheme I & Ranking $Y\left(A_{i}\right)$ \\
\hline 1 & 3 \\
2 & 4 \\
3 & 2 \\
4 & 1 \\
\hline
\end{tabular}

Reverse the relationship $a$, get the strong preference relationship $a^{\prime}$, i.e., $A_{2} P A_{1}, A_{1} P A_{3}$; reverse the relationship $b$, get the weak preference relationship $b^{\prime}$, i.e.,
$A_{1} Q A_{4}, A_{3} Q A_{4}, A_{2} Q A_{3}$. Using the same procedure for direct ranking, the reverse ranking $Y^{\prime}\left(A_{i}\right)$ is obtained, and the reverse ranking is the same as the direct ranking. Utilizing Eq. (7), we can get the final ranking $V\left(A_{i}\right)$. Table 11 presents the final ranking of the four alternatives.

Table 11. Final Ranking

\begin{tabular}{cc}
\hline Scheme I & Ranking $V\left(A_{i}\right)$ \\
\hline 1 & 3 \\
2 & 4 \\
3 & 2 \\
4 & 1 \\
\hline
\end{tabular}

Hence, the final ranking of the four alternatives is $A_{4} \succ A_{3} \succ A_{1} \succ A_{2}$, and obviously $A_{4}$ is the most desirable alternative.

\section{(4) Ranking the alternatives: PROMETHEE with proportional 2-tuple linguistic information}

Using the group comprehensive evaluation matrix $L$, we can obtain the preference difference $d_{j}\left(A_{i}, A_{k}\right)$ (Table 12).

After calculating the preference difference $d_{j}\left(A_{i}, A_{k}\right)$, the preference function and the threshold of each criterion can be obtained. Table 13 shows the preference function and the threshold of each criterion.

By following the steps described in Section 4.4, one can obtain the multi-attribute preference index $\pi\left(A_{i}, A_{k}\right)$ (Table 14).

Using Eqs. (10) and (11), the leaving flow $\phi^{+}\left(A_{i}\right)$, entering flow $\phi^{-}\left(A_{i}\right)$, and net flow $\phi\left(A_{i}\right)$ can be derived (Table 15). Therefore, the ranking of four alternatives is $A_{4} \succ A_{3} \succ A_{1} \succ A_{2}$, and obviously $A_{4}$ is the best among all alternatives.

Table 12. The preference difference $d_{j}\left(A_{i}, A_{k}\right)$

\begin{tabular}{cccccc}
\hline$d$ & $C_{1}$ & $C_{2}$ & $C_{3}$ & $C_{4}$ & $C_{5}$ \\
\hline$A_{1}, A_{2}$ & 0.0683 & 0.0836 & 0.0881 & -0.2242 & 0.1898 \\
$A_{1}, A_{3}$ & -0.1976 & -0.0488 & -0.2104 & -0.1956 & 0.2619 \\
$A_{1}, A_{4}$ & -0.7238 & -0.1411 & -0.0444 & 0.2218 & 0.3749 \\
$A_{2}, A_{3}$ & -0.2660 & -0.1324 & -0.2986 & 0.0285 & 0.0720 \\
$A_{2}, A_{4}$ & -0.7922 & -0.2247 & -0.1325 & 0.4460 & 0.1851 \\
$A_{3}, A_{4}$ & -0.5261 & -0.0922 & 0.1660 & 0.4174 & 0.1130 \\
\hline
\end{tabular}


Table 13. The preference function and threshold of each criterion

\begin{tabular}{lccccc}
\hline Criterion & $C_{1}$ & $C_{2}$ & $C_{3}$ & $C_{4}$ & $C_{5}$ \\
\hline Preference function & \multicolumn{5}{c}{ Criterion } \\
Threshold linear & preference \\
& 0.7922 & 0.2247 & 0.2986 & 0.446 & 0.3749 \\
\hline
\end{tabular}

Table 14. The multi-attribute preference index $\pi\left(A_{i}, A_{k}\right)$

\begin{tabular}{lcccc}
\hline$\pi\left(A_{i}, A_{k}\right)$ & $A_{1}$ & $A_{2}$ & $A_{3}$ & $A_{4}$ \\
\hline$A_{1}$ & ---- & 0.2349 & 0.1347 & 0.2748 \\
$A_{2}$ & 0.0828 & ---- & 0.0476 & 0.2599 \\
$A_{3}$ & 0.2581 & 0.3231 & ---- & 0.2528 \\
$A_{4}$ & 0.4647 & 0.6019 & 0.3192 & ---- \\
\hline
\end{tabular}

Table 15. The leaving, entering and net flows.

\begin{tabular}{ccccc}
\hline Alternatives & $A_{1}$ & $A_{2}$ & $A_{3}$ & $A_{4}$ \\
\hline$\phi^{+}\left(A_{i}\right)$ & 0.6444 & 0.3903 & 0.8340 & 1.3858 \\
$\phi^{-}\left(A_{i}\right)$ & 0.8056 & 1.1599 & 0.5015 & 0.7875 \\
$\phi\left(A_{i}\right)$ & -0.1612 & -0.7696 & 0.3325 & 0.5983 \\
\hline
\end{tabular}

\section{Conclusion, limitation and future research}

In decision-making problems, the linguistic term sets which are not uniformly and symmetrically distributed may be used to express decision makers' opinions. The proportional 2-tuple linguistic model provides a way to deal with this type of linguistic term sets. This study further develops multi-attribute group decision making methods with linguistic assessments and linguistic weights, based on the proportional 2-tuple linguistic model. The main points presented are as follows:

(1) Some new operations in proportional 2-tuple linguistic model are defined, they are the weighted average aggregation operator with linguistic weights, ordered weighted average operator with linguistic weights and the distance between proportional linguistic 2-tuples.

(2) Four multi-attribute group decision making methods are presented. They are the method based on the proportional 2-tuple linguistic aggregation operator, TOPSIS with proportional 2-tuple linguistic information, ELECTRE with proportional 2-tuple linguistic information, and PROMETHEE with proportional 2tuple linguistic information.

Meanwhile, the methodologies based on unbalanced linguistic term $\operatorname{sets}^{22,28}$ can deal with the linguistic term sets which are not uniformly and symmetrically distributed. So, we argue that our study has a limitation: a comparative analysis between our model and the methods based on unbalanced linguistic term sets need to be proposed. In the future, we will pursue this topic. Moreover, we will discuss some possible applications of our model (e.g., new product development ${ }^{31}$ and emergency management evaluation ${ }^{50}$ ).

\section{Acknowledgements}

Yucheng Dong would like to acknowledge the financial support of a Grant (No. 71171160) from NSF of China, and a Grant (No. skqx201308) from Sichuan University.

\section{References}

1. A. Albadvi, S.K. Chaharsooghi and A. Esfahanipour, Decision making in stock trading: an application of PROMETHEE, Eur. J. Oper. Res. 177 (2007) 673-683.

2. S. Alonso, F.J. Cabrerizo, F. Chiclana, F. Herrera and E. Herrera-Viedma, Group decision-making with incomplete fuzzy linguistic preference relations, Int. J. Intell. Syst. 24(2) (2009) 201-222.

3. S. Alonso, F. Chiclana, F. Herrera, E. Herrera-Viedma, J. Alcalá-Fdez and C. Porcel, A consistency-based procedure to estimate missing pairwise preference values, Int. J. Intell. Syst. 23(2) (2008) 155-175.

4. M. Behzadian, R.B. Kazemzadeh, A. Albadvim and M. Aghdasi, PROMETHEE: a comprehensive literature review on methodologies and applications, Eur. J. Oper. Res. 200 (2010) 198-215.

5. R. Benayoun, B. Roy and N. Sussmann, Manual de reference du programme electre. Note De Synthese et Formation, No. 25, Direction Scientifique SEMA, Paris, France, 1966.

6. F.J. Cabrerizo, S. Alonso and E. Herrera-Viedma, A consensus model for group decision making problems with unbalanced fuzzy linguistic information, Int. J. Inf. Tech. Decis. Making 8(1) (2009) 109-131.

7. F.J. Cabrerizo, I.J. Pérez and E. Herrera-Viedma, Managing the consensus in group decision making in an unbalanced fuzzy linguistic context with incomplete information, Knowl.- Based Syst. 23 (2010) 169-181.

8. F. Chiclana, E. Herrera-Viedma, F. Herrera and S. Alonso, Some induced ordered weighted averaging operators and their use for solving group decision-making 
problems based on fuzzy preference relations, Eur. J. Oper. Res. 182(1) (2007) 383-399.

9. R. Degani and G. Bortolan, The problem of linguistic approximation in clinical decision making, Int. J. Approx. Reason 2(2) (1988) 98-162.

10. M. Delgado, J.L. Verdegay and M.A. Vila, On aggregation operations of linguistic labels, Int. J. Intell. Syst. 8(3) (1993) 351-370.

11. Y.C. Dong, W.C. Hong, Y.F. Xu and S. Yu, Selecting the individual numerical scale and prioritization method in the analytic hierarchy process: A 2-tuple fuzzy linguistic approach, IEEE Trans. Fuzzy Syst. 19 (2011) 13-25.

12. Y.C. Dong, Y.F. Xu, H.Y. Li and B. Feng, The OWAbased consensus operator under linguistic representation models using position indexes, Eur. J. Oper. Res. 203 (2010) 455-463.

13. Y.C. Dong, Y.F. Xu and S. Yu, Computing the numerical scale of the linguistic term set for the 2-tuple fuzzy linguistic representation model, IEEE Trans. Fuzzy Syst. 17 (2009) 1366-1378.

14. Y.C. Dong, Y.F. Xu and S. Yu, Linguistic multi-person decision making based on the use of multiple preference relations, Fuzzy Sets Syst. 160 (2009) 603-623.

15. M. Espinilla, J. Liu and L. Martínez, An extended hierarchical linguistic model for decision-making problems, Comput. Intell. 27(3) (2011) 489-512.

16. Z.P. Fan, B. Feng and W.L. Suo, A fuzzy linguistic method for evaluating collaboration satisfaction of NPD team using mutual-evaluation information, Int. J. Prod. Econ. 122(2) (2009) 547-557.

17. S. Greco, M. Kadzinski, V. Mousseau, R. Slowinski, ELECTRE $^{\mathrm{GKMS}}$ : robust ordinal regression for outranking methods, Eur. J. Oper. Res. 214(1) (2011) 118-135.

18. C. Hermans, J. Erickson, T. Noordewier, A. Sheldon and M. Kline, Collaborative environmental planning in river management: an application of multi-criteria decision analysis in the White River Watershed in Vermont, $J$. Environ. Manage. 84 (2007) 534-546.

19. F. Herrera, S. Alonso, F. Chiclana and E. HerreraViedma, Computing with words in decision-making: Foundations, trends and prospects, Fuzzy Optim. Decis. Making 8(4) (2009) 337-364.

20. F. Herrera and E. Herrera-Viedma, Aggregation operators for linguistic weighted information, IEEE Trans. Syst., Man, Cybern. A, Syst. 27(5) (1997) 646-656.

21. F. Herrera and E. Herrera-Viedma, Linguistic decision analysis: Steps for solving decision problems under linguistic information, Fuzzy Sets Syst. 115(1) (2000) 6782.

22. F. Herrera, E. Herrera-Viedma and L. Martínez, A fuzzy linguistic methodology to deal with unbalanced linguistic term sets, IEEE Trans. Fuzzy Syst. 16(2) (2008) 354-370.
23. F. Herrera, E. Herrera-Viedma and J.L. Verdegay, Direct approach processes in group decision making using linguistic OWA operators, Fuzzy Sets Syst. 79(2) (1996) 175-190.

24. F. Herrera and L. Martínez, A 2-tupie fuzzy linguistic representation model for computing with words, IEEE Trans. Fuzzy Syst. 8(6) (2000) 746-752.

25. F. Herrera and L. Martínez, A model based on linguistic 2-tuples for dealing with multi-granularity hierarchical linguistic contexts in multi-expert decision-making, IEEE Trans. Syst. Man Cybern. B, Cybern. 31(2) (2001) 227234.

26. F. Herrera and L. Martínez, The 2-tuple linguistic computational model advantages of its linguistic description, accuracy and consistency, Int. J. Unc. Fuzz. Knowl.-Based Syst. 9(suppl.) (2001) 33-48.

27. E. Herrera-Viedma, F. J. Cabrerizo, I. J. Pérez, M. J. Cobo, S. Alonso and F. Herrera, Applying Linguistic OWA Operators in Consensus Models under Unbalanced Linguistic Information, Studies in Fuzziness and Soft Comp. 265 (2011) 167-186.

28. E. Herrera-Viedma and A.G. López-Herrera, A model of information retrieval system with unbalanced fuzzy linguistic information, Int. J. Intell. Syst. 22(11) (2007) 1197-1214.

29. C.L. Hwang and K.P. Yoon, Multiple attributes decisionmaking methods and applications, Heidelberg: Springer, 1981.

30. J. Lawry, An alternative approach to computing with words, Int. J. Uncertain. Fuzz. 11(9) (2001) 3-16.

31. J. Lu, J. Ma, G. Zhang, Y. Zhu, X. Zeng and L. Koehl, Theme-based comprehensive evaluation in new product development using fuzzy hierarchical criteria group decision-making method, IEEE Trans. Ind. Electron. 58(6) (2011) 2236-2246.

32. L. Martínez, M. Espinilla, J. Liu, L.G. Pérez and P.J. Sánchez, An evaluation model with unbalanced linguistic information applied to olive oil sensory evaluation, $J$. Multi-Valued Log. S. 15 (2009) 229-251.

33. L. Martínez, M. Espinilla and L.G. Pérez, A linguistic multigranular sensory evaluation model for olive oil, Int J. Comp. Intell. Syst. 1(2) (2008) 148-158.

34. L. Martínez and F. Herrera, An overview on the 2-tuple linguistic model for computing with words in decision making: Extensions, applications and challenges, Inf. Sci. 207 (2012) 1-18.

35. L. Martínez, J. Liu, D. Ruan and J.B. Yang, Dealing with heterogeneous information in engineering evaluation processes, Inf. Sci. 177(7) (2007) 1533-1542.

36. L. Martínez, D. Ruan and F. Herrera, Computing with words in decision support systems: An overview on models and applications, Int. J. Comp. Intell. Syst. 3(4) (2010) 382-395. 
37. S. Massanet, J.V. Riera, J. Torrens and E. HerreraViedma, A new linguistic computational model based on discrete fuzzy numbers for computing with words, Inf. Sci. 258 (2014) 277-290.

38. M.M. Marzouk, ELECTRE III model for value engineering applications, Automat. Constr. 20 (2011) 596-600.

39. J. M. Mendel, Historical reflections and new positions on perceptual computing, Fuzzy Optim. Decis. Making 8(4) (2009) 325-335.

40. J.M. Mendel and D. Wu, Perceptual computing: Aiding people in making subjective judgments, New Jersey: IEEE Press and John Wiley, 2010.

41. D. Meng and Z. Pei, On weighted unbalanced linguistic aggregation operators in group decision making, Inf. Sci. 223 (2013) 31-41.

42. R.M. Rodríguez and L. Martínez, An analysis of symbolic linguistic computing models in decision making, Int. J. Gen. Syst. 42(1) (2013) 121-136.

43. R.M. Rodríguez, L. Martínez and F. Herrera, Hesitant fuzzy linguistic term setsfor decision making, IEEE Trans. Fuzzy Syst. 20(1) (2012) 109-119.

44. J.H. Wang and J.Y. Hao, A new version of 2-tuple fuzzy linguistic representation model for computing with words, IEEE Trans. Fuzzy Syst. 14(3) (2006) 435-445.

45. J.H. Wang and J.Y. Hao, An approach to computing with words based on canonical characteristic values of linguistic labels, IEEE Trans. Fuzzy Syst. 15(4) (2007) 593-604.

46. J.H. Wang and J.Y. Hao, Fuzzy linguistic PERT, IEEE Trans. Fuzzy Syst. 15(2) (2007) 133-144.

47. Z.S. $\mathrm{Xu}, \mathrm{A}$ method based on linguistic aggregation operators for group decision making with linguistic preference relations, Inf. Sci. 166 (2004) 19-30.

48. L.A. Zadeh, The concept of a linguistic variable and its applications to approximate reasoning, Part I, Inf. Sci. 8 (1975) 199-249.

49. L.A. Zadeh, Fuzzy logic $=$ computing with words, IEEE Trans. Fuzzy Syst. 4 (1996) 103-111.

50. G. Zhang, J. Ma and J. Lu, Emergency management evaluation by a fuzzy multi-criteria group decision support system, Stoch Environ. Res. Risk Assess. 23(4) (2009) 517-527. 